\title{
Core-shell Fibers for Biomedical Applications-A Review
}

\section{Md. Fazley Elahi*, Wang Lu, Guan Guoping and Farzana Khan}

Key Laboratory of Textile Science and Technology of Ministry of Education, College of Textiles, Donghua University, Songjiang district, Shanghai, China

\begin{abstract}
Now is the age of high-tech research and development. Different types of fibers have been produced in the last decades for the benefit of human needs. Core-shell nanofibers are a revolutionary development in the field of science and technology. Preparation of nanoscale fibers in a core-shell configuration, using two dissimilar materials, via a novel technique of electrospinning has presented unusual potential for use in many novel applications. The studies have addressed issues related to the technology involved and examined the suitability of the technique for producing unique nanoscale morphologies involving variety of materials. Numerous studies have been published on the preparation of core-shell nanofibers by electrospinning process for developing novel structures for new applications. No major review of the co-axial electrospinning process has appeared to the knowledge of the authors but is needed in order to develop a fuller understanding of the status of work in this field. After a brief introduction to the conventional electrospinning process, this paper focuses on the preparation and uses of core-shell fibers by electrospinning studies published to date. It attempts to categorize them in terms of the approaches adopted, and highlights the knowledge gained with respect to the material and process parameters that impact the size and the uniformity of the core-shell nanofibers obtained.
\end{abstract}

Keywords: Core-shell; Co-axial electrospinning; Nanofibers; Microencapsulation; Nanotechnology

\section{Introduction}

The application of nanostructures in fields such as biomaterials, telecommunications, and computing has increased enormously in the recent past and has engaged the interests of scientists and engineers to invent new and novel structures involving nanofibers and efficient processes for producing them.

Nanostructures of different morphologies, including solid nanorods, nanowires, hollow cylinders, fibrils, spheres and micelles, nanofiber webs, foams with nano-structured walls and pores, and nanopatterned materials have been prepared using a number of methods. These include: self assembly, phase separation, template synthesis, lithography, and electrostatic spinning [1-4].

For producing nanofibrous structures for membrane applications, electrostatic spinning, or electrospinning, has emerged as a method of choice due to the simplicity of the technology and its cost effectiveness. In this technique, a charged polymer solution or a charged melt flowing out of a capillary is drawn by two or more orders of stretch, using a strong electrostatic field, to obtain nanofibers in the form of a nonwoven mesh. Under optimum solution or melt material properties and spinning conditions, fibers of the order of $100 \mathrm{~nm}$ could be obtained. Due to very high surface area to volume ratio and high porosity with interconnected pore network, the polymeric nanofibrous structures are being explored with interest in abroad range of applications: such as drug delivery vehicles, scaffolds for tissue engineering of the skin, blood vessel, ligament, nerve, cartilage as well as the bone fixtures $[5,6]$

In recent years, many modifications have been made in the basic electrospinning process in order to enhance the quality and improve the functionality of the resulting nanofiber structures. One such modification that has gained much attention and holds great promise in a variety of applications is preparation of core-shell bicomponent nanofiber structures using "co-axial electrospinning" are also called "two-fluid electrospinning". In this process, two dissimilar materials are delivered independently through a co-axial capillary and drawn to generate nanofibers in core-sheath configuration. Increasing need for the manufacture of two material based structures in which one is surrounded by the other or in which the particles of one are encapsulated in the matrix of the other, at the micro or nano level, shows potential for a wide range of uses [7-10]:

1. Isolating an unstable component and minimizing its chances of decomposition under a highly reactive environment.

2. Releasing with time a substance to a particular receptor.

3. Reinforcing a material to improve its mechanical properties.

4. Serving as scaffold for engineering tissues in which a less biocompatible polymer is surrounded by a more biocompatible material.

\section{Technology and Control of Electrospinning}

The electrospinning process consists of a polymer solution, or melt, that is placed in a syringe or pipette. The tip of the pipette or needle that is attached to the syringe is charged with a voltage, and when the electric field produces a force that overcomes the surface tension of the solution, a jet of polymer is drawn from the syringe and attracted to a grounded collecting plate placed some distance away from the needle.

The jet forms a Taylor Cone immediately after leaving the needle, and as it travels toward the grounded target, the solution gradually evaporates, leaving small fibers to collect on the target. The charge from the fibers dissipates into the surrounding environment, and a non-

*Corresponding author: Md. Fazley Elahi, Key Laboratory of Textile Science and Technology of Ministry of Education, College of Textiles, Donghua University, Songjiang district, Shanghai, China, E-mail: elahitex@yahoo.com

Received December 19, 2012; Accepted January 31, 2013; Published February 04, 2013

Citation: Elahi MF, Lu W, Guoping G, Khan F (2013) Core-shell Fibers for Biomedical Applications-A Review. J Bioengineer \& Biomedical Sci 3: 121 doi:10.4172/2155-9538.1000121

Copyright: (C) 2013 Elahi MF, et al. This is an open-access article distributed under the terms of the Creative Commons Attribution License, which permits unrestricted use, distribution, and reproduction in any medium, provided the original author and source are credited. 
woven fiber mat consisting of tiny fibers, ranging from $50 \mathrm{~nm}$ to $10 \mu \mathrm{m}$, is formed on the target [11-14] (Figure 1).

Processing parameters including solution properties (viscosity, elasticity, conductivity, and surface tension), processing conditions (voltage, needle diameter, distance from the needle to the grounded target), and the environment (temperature, humidity, and static electricity) can be varied to modify the fibers for individual applications. For example, fiber diameter increases with increasing polymer concentration and increasing voltage $[11,15,16]$.

This fabrication technique has many attractive features to produce scaffolds for tissue engineering applications. For one, the mechanical properties of the scaffolds can be adjusted by changing the orientation of the fibers (parallel alignment or random arrangement), and the types of polymer(s) used (natural vs. synthetic). In addition to altering the orientation of the fibers, variations in the scaffolds themselves can be obtained for different applications. For example, multilayering electrospinning results in a hierarchically ordered structure composed of different types of polymers, while multicomponent electrospinning, where multiple polymers are simultaneously electrospun together, forms a mixed fiber mesh [17]. Also, the way the fibers are collected on the grounded target can influence the fiber orientation as well as scaffold fabrication. Collection schemes currently used include a single ground, rotating single ground, dual bar, dual ring, single horizontal ring, electrospinning in vitro onto cells, or electrospinning cells with polymer (Figure 2) [18].

\section{Polymers used in Core-shell Electrospinning}

Many different polymers have been electrospun relatively successfully in a solution or melt form. These have included synthetic materials (polyesters, polyamides, polyurethanes, polycarbonates, polysulfones, etc.), natural materials (collagen, gelatin, elastin, chitosan, silk etc.), and synthetic biodegradable polymers (polyglycolic acid, polycaprolactone, polylactic acid, polylactide-co-glycolide, etc.). Major applications to date, some for prototype products, have included [6] tissue engineering scaffolds, drug delivery devices, and wound dressings; membranes resistant to biochemical gases and efficient in aerosol trapping; liquid, gas, and molecular filters; in photovoltaic and LCD devices, as electromagnetic interference shields, and in thermomechanical and biochemical sensor devices etc.

\section{Why Core-shell Fibers?}

The loss or failure of critical tissues is one of the most frequent and devastating problems in human health care. Tissue regeneration involves the preparation of polymeric structures that serve as degradable scaffolding for bioactive molecules or cells as well as the study of their



Figure 1: Electrospinning setup [15].
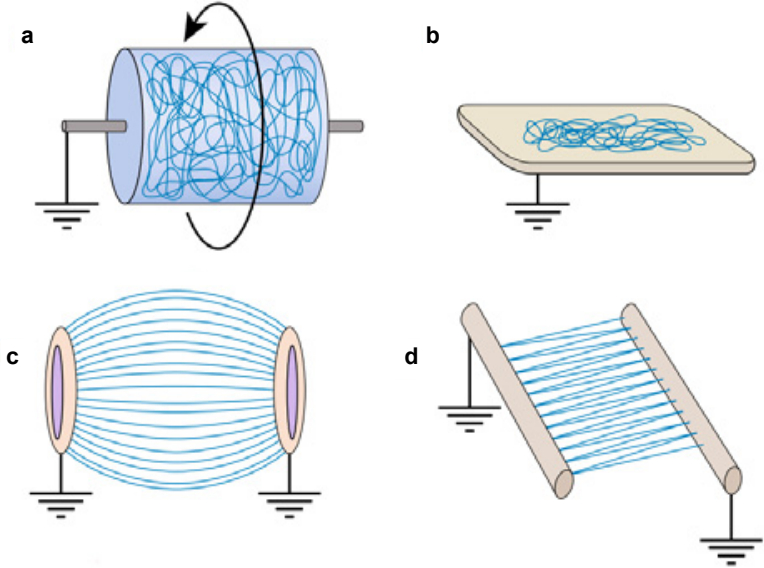

e
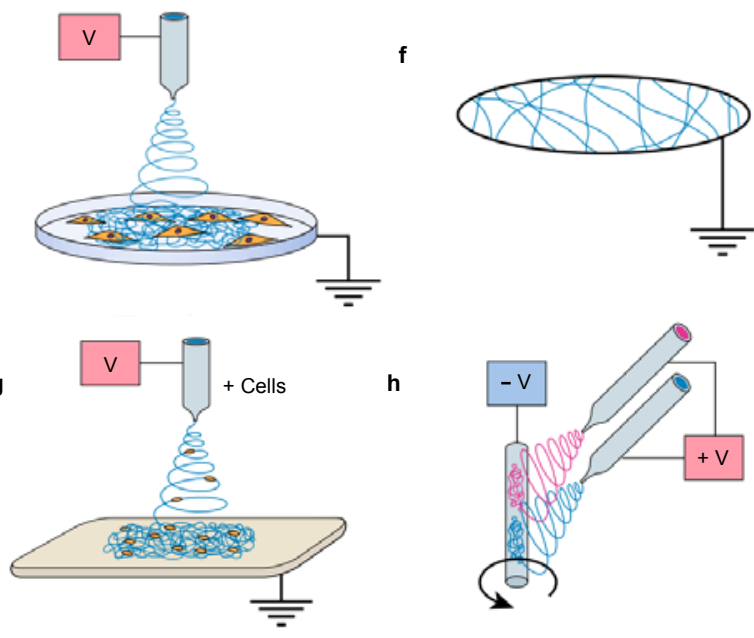

i
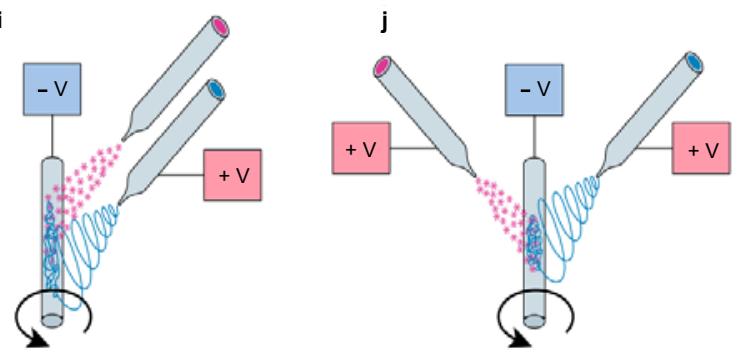

Figure 2: Different electrospinning collecting schemes. (a) Rotating single ground, (b) single ground, (c) dual ring, (d) dual bar, (e) electrospinning in vitro onto cells, (f) single horizontal ring (g) electrospinning cells with polymer, (h) dual spinneret electrospinning (with second pink fibers), (i) electrospinning/electrospraying with parallel and (j) perpendicular spinnerets.

structure and properties [19]. However, the key problem of how to incorporate bioactive molecules into thin delicate structures that construct devices and scaffolds remains, since they must be incorporated into dense polymeric structures without adversely affecting either the scaffold's properties or the agent's activity. Conventional scaffolds for tissue regeneration are usually composed of bioresorbable fibers that build bulky porous structures. Biologically active molecules are located in the pores, between adjacent fibers. Core-shell fibers have been developed and studied special implants, made of bioresorbable fibers, in which the biologically active molecules are incorporated within the fibers. Such unique scaffolds are ideal when thin, delicate structures are 
needed, but they are beneficial also as basic elements of conventional bulky structures, due to better release profile control. They can also be used to build implants that combine drug release with other functions, such as mechanical support.

\section{Manufacturing Process of Core-shell Fiber}

In the present time, there are two most common processes to produce core-shell fibers, such as:

1. Co-axial electrospinning

2. Emulsion electrospinning

\section{Core-shell fibers from co-axial electrospinning}

In this section, the basic setup and the process of co-axial electrospinning is described. Also discussed are the effects of and the requirements for different material and process parameters to achieve uniform core-shell structures.

General set up and the process: The general set up adopted by most researchers is quite similar to that used for electrospinning described in section [2]. A modification is made in the spinneret by inserting a smaller (inner) capillary that fits concentrically inside the bigger (outer) capillary to make co-axial configuration (Figure 3). The outer needle is attached to the reservoir containing the sheath solution and the inner is connected to the one holding the core solution. The arrangement could be horizontal as shown in figure 1 or vertical as illustrated in figure 3 . The feeding rates of the solutions are controlled using either metering pumps [20] or air pressures [21]. In some studies, the sheath solution was even exposed to the atmospheric pressure and allowed to flow due to gravity $[8,10,22]$. The arrangement required in these cases was vertical. Coaxial spinning could also be conducted using polymer melts, for which a heating system is used that surrounds the reservoir [23]. The co-axial set up expectedly requires a carefully designed and manufactured co-axial spinneret. A slightly different and much simpler set up has been reported recently, in the study by Wang et al. [24] which obviates the need for inserting one capillary into the other. The design consists of two separate syringes with different sized capillaries but the smaller capillary is inserted from outside into the Taylor cone formed at the exit of the bigger capillary (Figure 4).

The process of co-axial electrospinning is conceptually similar to that of the single jet electrospinning $[11,25]$. When the polymer solutions are charged using high voltage, the charge accumulation

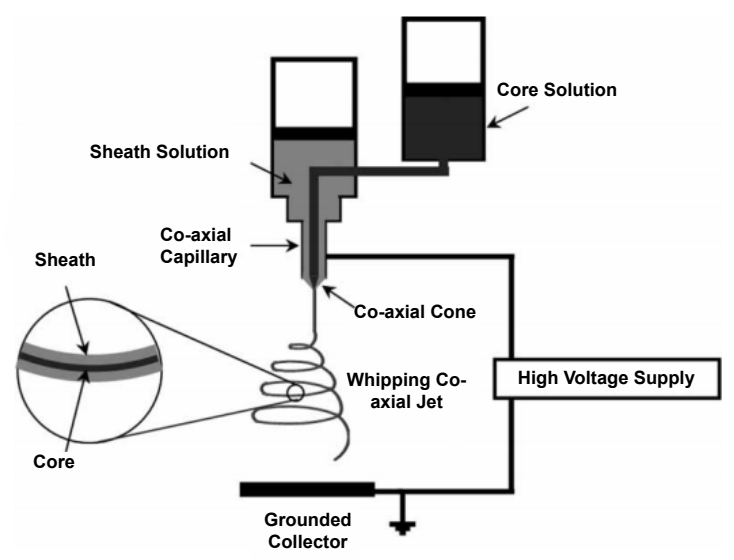

Figure 3: Schematic of co-axial electrospinning set-up.

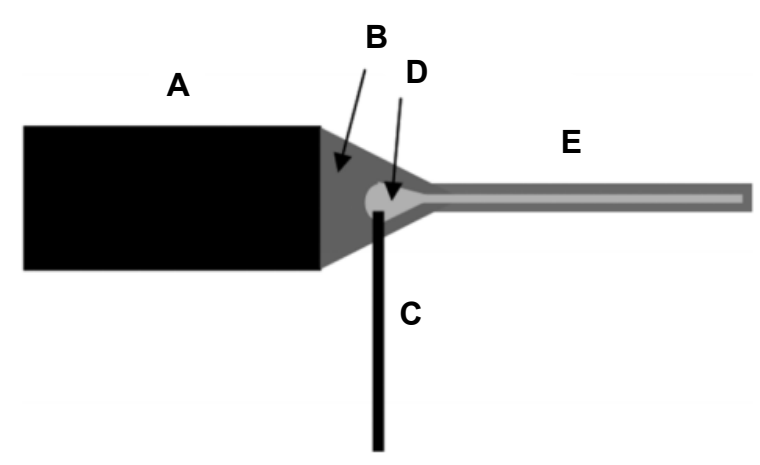

Figure 4: Schematic of the alternative set-up for co-axial electrospinning. A: Bigger capillary carrying sheath solution, B: Taylor cone from the sheath solution, C: Smaller capillary carrying core solution, inserted directly into the cone formed from the sheath solution, D: Taylor cone from the core solution formed co-axially inside the sheath Taylor cone, E: Co-axial jet.

occurs predominantly on the surface of the sheath liquid coming out of the outer co-axial capillary [25]. The pendant droplet of the sheath solution elongates and stretches due to the charge-charge repulsion to form a conical shape and once the charge accumulation reaches a certain threshold value due to the increased applied potential, a fine jet extends from the cone. The stresses generated in the sheath solution cause shearing of the core solution via viscous dragging and contact friction [26]. This causes the core liquid to deform into the conical shape and a compound co-axial jet develops at the tip of the cones. This is illustrated in figure 5.

It is expected that as long as the compound cone is stable, the core is uniformly incorporated into the sheath for core-sheath fiber formation. On the way to the collector, as it happens in the single fluid electrospinning, the jet undergoes bending instability and follows a back and forth whipping trajectory, during which the two solvents evaporate, and the core-shell nanofibers are formed [21].

Since the process of co-axial electrospinning is similar to that of the conventional electrospinning, all variables that govern the quality of the process and the morphology of the fibers in the latter also affects the behavior in the former. Additionally, as the sheath and the core solutions are in contact and undergo the same bending instability and whipping motion, the degree of dissimilarity between them, in terms of composition, and physical and rheological properties, plays an important role in the formation of the composite fiber.

Material parameters: Solution viscosities: In the co-axial electrospinning, the sheath solution acts as a guide and surrounds the core material. The viscosity of the sheath solution is required to be such that the viscous stress imparted by it on the core is sufficient to overcome the interfacial tension between the two solutions and allows the formation of a compound Taylor cone and a jet from the latter [27]. Accordingly, viscosity of the sheath solution is critical and the sheath polymer-solvent system selected should be electrospinnable by itself to lend to core-sheath structure formation [20]. From the studies available, it appears that the requirements for the spinnability of the core solution by itself are not as critical as they are for the sheath material. As suggested by Yu et al. [20], the jet break-up of the core fluid tends to be prevented by the sheath via two mechanisms: strain hardening of the interface between the sheath and the core due to rapid stretching that occurs during whipping; and lesser surface forces acting on the core solution surrounded by the sheath, which otherwise will be higher if the contact of the core was with air, as will be true if the core fluid was 
electrospun by itself. However, in several studies, jet break-up of the core was still observed [27-29] if the viscosity of the core was too low [29]. Accordingly, the core fluid must also possess a certain minimum viscosity if it is to be entrained continuously without break-up. Clearly, further work is needed to quantify the exact viscosity requirements for the sheath and the core fluids in co-axial electrospinning.

Solution concentration: In a conventional single fluid electrospinning, increase in solution concentration has been shown to give an increase in the fiber diameter due to the presence of more material in the jet. A similar effect has been observed in the case of co-axial electrospinning. Zhang et al. [8] experimented with the concentration of the core solution while keeping that of the sheath constant. They reported that the increase in the core concentration increased both the core and overall fiber diameters. They also found, as expected, that with an increase in the core diameter, the thickness of the sheath decreased [8], which was due to the same mass of the sheath distributed over a larger core (Figure 6).

Similarly, He et al. [29] observed an increase in the overall fiber diameter when higher sheath concentration was used in the solution with the core solution concentration maintained at a constant concentration [30]; this was due to an increase in the sheath thickness. Figure 7 shows PP/PLA core-shell fibers cross sectioned and imaged with FIB. In figure 8, mechanical drawing of core-shell fibers has been shown.

Solvent/Solution miscibility and incompatibility: The interaction between the core and the sheath solutions (polymers or solvents) is an important parameter to be considered before selecting the desired set for co-axial electrospinning. First of all, for successful spinning, the solvent in either of the solutions should not precipitate the polymer



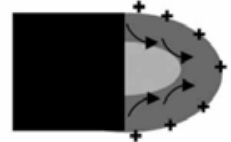

B

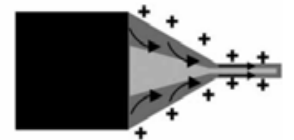

Figure 5: Schematic illustration of compound Taylor cone formation. A: Surface charges on the sheath solution, B: viscous drag exerted on the core by the deformed sheath droplet, C: Sheath- core compound Taylor cone formed due to continuous viscous drag.

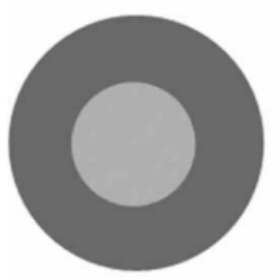

A

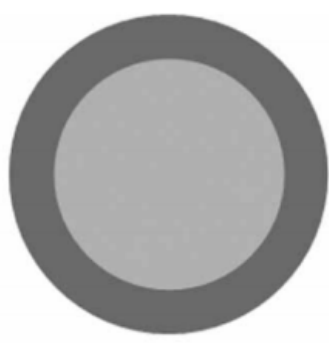

B
Figure 6: Schematic showing effect of core diameter on sheath thickness. A: Smaller core diameter and larger sheath thickness; B: Larger core diameter and smaller sheath thickness.


Figure 7: PP/PLA core-shell fibers cross sectioned and imaged with FIB. (A) PLA core/PP shell with PLA: PP mass ratio of 50:50. PP core/PLA shell with PP: PLA mass ratios of (B) 15:85, (C) 50:50 and (D) 90:10. Fibers were all collected at an aspirator pressure of $25 \mathrm{psi}$ [30].

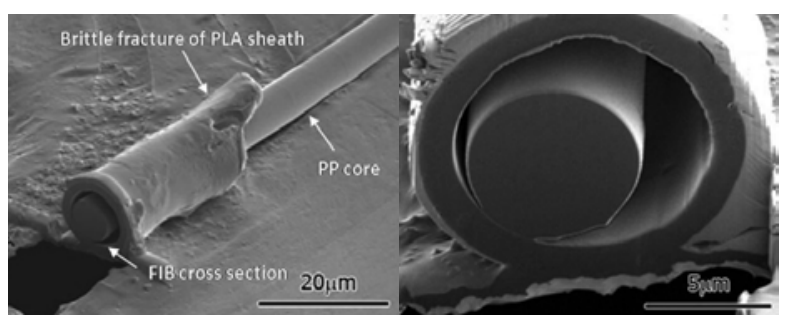

Figure 8: Core-shell fibers with $50 \mathrm{wt} \%$ core $/ 50 \mathrm{wt} \%$ sheath showing fracture after mechanical drawing [30].

from the other solution when the solutions meet at the tip of the capillary [20]. Secondly, the interfacial tension between the sheath and the core should be as low as possible for the generation of the stabilized compound Taylor cone [27].

The opinions of different researchers, however, diverge on the issue of miscibility of the sheath and core solutions. In a report by Sun et al. [21], the authors showed that "the characteristic time of diffusion spreading of a boundary" between two miscible solutions was greater than that of the electrospinning process and therefore, no mixing took place. They supported this hypothesis experimentally by using the solution of PEO in a water- ethanol mixture for both the sheath and the core, only differing in the concentration. A subsequent study by Yu et al. [20] was in agreement with this finding and they added that using the same solvent might also help reduce the interfacial tension between the two solutions, which should further favor the development of a uniform core-shell fiber.

Li and Xia [26] in their study, on the other hand, reported that mixing between the solutions could occur during the process if they were miscible. In an effort to make hollow nanofibers, they used two immiscible solutions PVP and the ceramic precursor $\mathrm{Ti}(\mathrm{OiPr})_{4}$ in the sheath and mineral oil in the core, and obtained uniform hollow fibers after extraction of the oil. They repeated the experiment by replacing the mineral oil by a miscible PVP solution in ethanol as the core and no hollow structure was present after removal of the PVP polymer. 
They further demonstrated the concept of mixing by using another set of miscible systems (PVP-Ti(OiPr) ${ }_{4}$ in ethanol, and polystyrene in the mixture of DMF and THF) in which only the solvents were miscible. They obtained a porous structure after removing the core polymer from the resultant fibers which again proved mixing. Despite these results, a few subsequent studies $[22,29,31,32]$ have reported the use of miscible or same sheath-core solvents to successfully obtain core-sheath fibers. The above observations based on limited work suggest that a clearer understanding of the conditions that would restrict mixing when miscible polymer-solvent systems are used needs to be developed through further research.

Solvent vapor pressure: The type of solvent used, in particular in the core solution, can also have a strong effect on the resulting morphology of the core-sheath structure. In a study by Li et al. [33], it was reported that high vapor pressure solvent i.e. the solvent that evaporates rapidly (e.g., chloroform, acetone etc.), when used in the core creates a thin layer at the interface of the sheath and the core due to rapid evaporation. This layer tends to trap the interior solvent that diffuses out more slowly due to the newly created barrier. When it fully leaves the somewhat solidified structure, it creates a vacuum; this causes the core structure to collapse from the round to ribbon-like configuration under atmospheric pressure [33]. The authors' speculation was based on the result that ribbon shaped fibers were obtained after the removal of the sheath when the core solution, composed of a conjugated polymer dissolved in chloroform, was used. This result coincided with our own finding that a collapsed structure was formed when chloroform was used as a solvent for the core polymer (Figure 9) [34]. In this experiment, the sheath solution used was poly(vinyl alcohol) in water and the core was poly(ethylene oxide) dissolved in chloroform.

Since the stabilized compound Taylor cone and the initial jet are the requirements for the co-axial electrospinning, high vapor pressure solvents may also not be used in the sheath solution as they may produce unstable Taylor cones [35] and lead to multiple jets due to fast evaporation. Such unstable Taylor cones can cause the formation of irregular core-sheath structures as well and result in separate fibers from the two solutions.

Solution conductivities: Another parameter affecting the quality of fibers produced by the electrospinning process is the conductivity of the solution. Solutions characterized by high conductivity have high surface charge density, which causes an increase in the elongational force on the jet due to self-repulsion of the excess charges under a given electrical field. This has been shown to produce smaller diameter fibers through an enhancement of the whipping action [36,37].

Conductivity difference between the shell and the core solutions can also affect core-sheath fiber formation. Yu et al. [20] speculated,

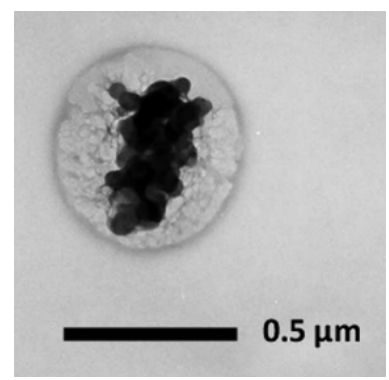

Figure 9: TEM cross-section of the core-sheath nanofiber depicting collapse of the core (dye added in the core solution to create contrast) [34]. based on their finding about separate spinning of fibers from the sheath and the core solutions, that more conductive core solution was pulled at a higher rate by the applied electric field and caused discontinuity in the core-sheath structure. Higher sheath conductivity, on the other hand, would not hinder the process of core-shell fiber formation but would rather result in higher shear stress on the core material and its subsequent elongation to form a thinner core [26]. It is also clear from the studies that even non-conductive or less conductive liquids can be successfully incorporated as the core into a higher conducting shell.

Process parameters: Applied voltage: The effect of applied voltage is not reported widely in the co-axial electrospinning literature except in a study by Li and Xia [26]. They showed that both the inner and the outer diameters of the hollow fiber de-creased on increasing the strength of the electric field. In all other studies, only one value of the applied potential has been reported that produced a stabilized compound Taylor cone and jet polymer solution for co-axial electrospinning process should have the following properties:

1. Electrospinnable sheath solution.

2. Higher sheath solution viscosity.

3. Low interfacial tension between the sheath and the core solutions.

4. Use of low vapor pressure solvents.

5. Higher sheath solution conductivity.

Moghe et al. [34] reported that for a given pair of polymer solutions, there existed a small range of applied voltage in which a stable compound Taylor cone was formed (Figure 10b). This range varied with the type of polymers used. Voltage below the critical range caused dripping of the two solutions followed by an intermittent jet from the sheath (Figure 10a) with an occasional incorporation of the core. Also, due to increased size of the cone, in our experience, mixing of the two solutions tended to occur if miscible solutions were used. Voltage above the critical range caused the strength of the electric field to exceed that required for the given material and the processing conditions and Taylor cones tended to recede and jets tended to emanate from inside the capillaries. This resulted into separate jets from the sheath and core solutions (Figures $10 \mathrm{c}$ and 11) and no core-sheath fibers formed. Instead, a structure with high variability in terms of fiber diameters was observed (Figure 12) that suggested different fiber formation from the sheath and the core solutions. In single fluid spinning, Dietzel et al. [38] also noted Taylor cone receding inside the capillary.

Solution flow rates: It has been uniformly accepted that the flow rates directly control the dimensions of the sheath and the core layers in co-axial electrospinning. For such spinning, however, special attention must be paid to the difference in the flow rates of the two solutions. It has been reported that when the sheath flow rate and other operating conditions are maintained at fixed values, there exists a range of core flow rates within which the formation of stabilized compound Taylor cone and the regular core-sheath structure are obtained. In other words, if the core flow rate is too low, an insufficient amount of solution is delivered and a continuous incorporation of the core into the sheath does not occur. On the other hand, if the core flow rate is too high, the size of the core liquid Taylor cone increases to the point that the viscous drag applied by the sheath solution is insufficient to confine the core solution within the cone. This causes the inner cone to lose its 


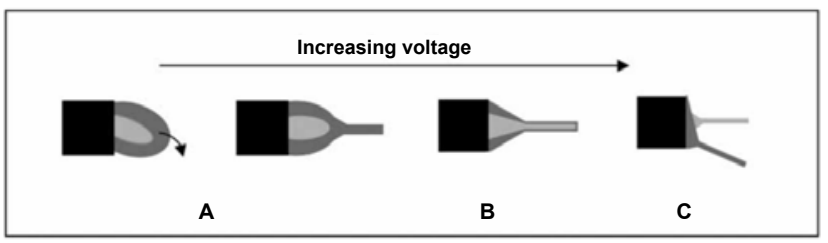

Figure 10: Schematic of the voltage dependence of the core-sheath fiber formation in co-axial electrospinning (A: Subcritical voltage; B: Critical voltage; C: Supercritical voltage).

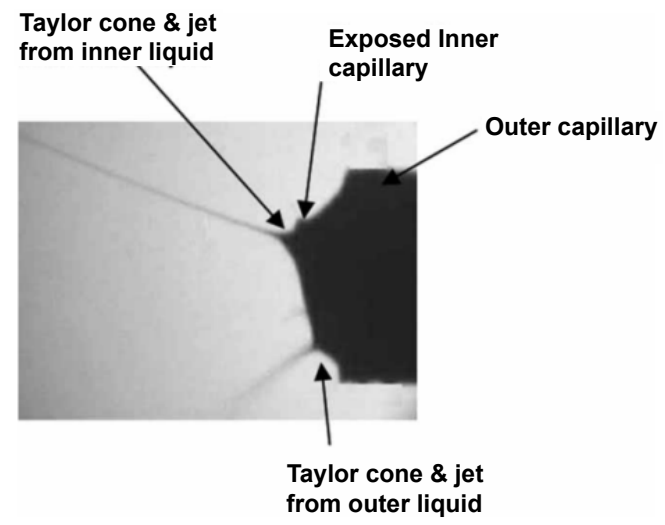

Figure 11: Separate fluid jets formed at supercritical voltage.
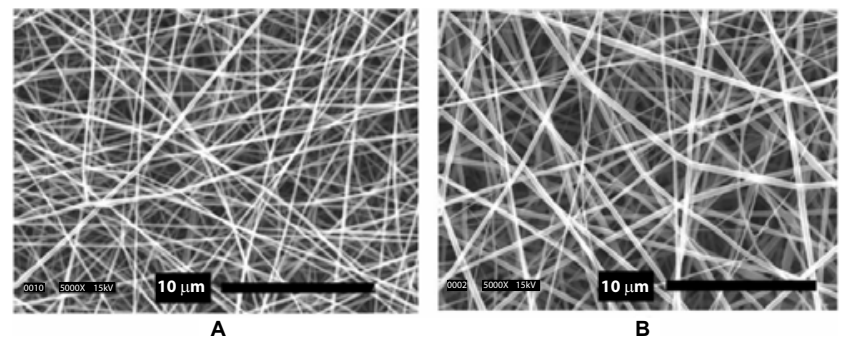

Figure 12: Effect of voltage on the morphology of the electrospun structure. A: structure obtained at critical voltage, B: Structure obtained at supercritical voltage. (Sheath: Gelatin; Core: PCL).

characteristic shape that, in turn, results into the mixing of inner and outer liquids [27]. In other words, the sheath fails to encapsulate the fast moving core uniformly and renders the overall process unstable $[20,32]$. For this reason, it is concluded that the core flow rate should generally be lower than that of the sheath.

Products, properties and applications from the co-axial electrospinning process: In this section, a brief review of the different types of co-axial structures produced is given. These are as follows:

1. Core-shell bicomponent nanofibers.

2. Fibers from non-electrospinnable materials.

3. Hollow fibers.

4. Fibers containing encapsulated microparticles.

Each of these structures has led to different applications and together they have greatly expanded the scope of the electrospinning technology in meeting the needs of the next generation polymer products.
Core-shell fibers from electrospinnable polymers: Core-sheath configuration provides potential for achieving unique properties from a product that are difficult to obtain from the constituent materials if spun separately. This approach can be broadly viewed as blending of materials, except that the two materials maintain their separate identities, with the core material completely surrounded by the sheath material. Core-sheath fiber formation could also be viewed as a one step process for obtaining a surface modified or a coated product. Various studies in this category, with their objectives, and materials used, are listed in table 2; the important results obtained from these are given below.

Feasibility study of producing such structures was first reported by Sun et al. [21]. The authors showed that the fiber formation process was sufficiently fast and, therefore, no mixing of the two solutions occurred. Subsequently, Zhang et al. (2004) [8] successfully demonstrated the feasibility of preparing core-shell nanofibers using two biodegradable materials-polycaprolactone (PCL) as the sheath and gelatin as the core, the structures suited for use in tissue engineering and drug delivery. The authors showed that the size of the core could be controlled by simply varying the core polymer solution concentration. In a more detailed study, the same group reported an improvement in the mechanical performance of the hybrid structure characterized by higher tensile strength and tensile strain (Figure 13) [22]. Gelatin and PCL, being natural and synthetic polymers respectively, degrade at different rates and therefore, the researchers suggested that such structure should be useful for applications such as drug delivery that may require different delivery rates at different times [22].

Along the same lines, Zhang et al. (2005) [10] prepared core-shell nanofiber structures under the premise that the surface biocompatibility can be enhanced by using a more biocompatible polymer as the sheath, which should provide improved cell-material interaction in tissue engineering applications. The researchers used collagen, a part of natural extracellular matrix, as the sheath, and PCL as the core and showed that the structure favored fibroblast cell proliferation and migration into the scaffold [10]. A more recent study published includes the use of poly(vinyl pyrrolidone) (PVP) (core) and poly(D,L-lactide) (PLA) (sheath) for potential drug delivery applications [39].

Core-shell fibers from non-electrospinnable materials: In this novel approach using the technique of co-axial electrospinning, it has been shown that the sheath could act as a template and guide the core

\begin{tabular}{|c|c|c|}
\hline Solution & Process & Environmental \\
\hline Parameters & Parameters & Conditions \\
\hline Concentration & Electrostatic Potential & Temperature \\
\hline Viscosity & Electric Field Strength & Humidity \\
\hline Surface Tension & Electrostatic Field Shape & Local Atmosphere Flow \\
\hline Conductivity & Working Distance & Atmospheric Composition \\
\hline Dielectric Constant & Feed Rate & Pressure \\
\hline Solvent Volatility & Orifice Diameter & \\
\hline
\end{tabular}

Table 1: Electrospinning process parameters.

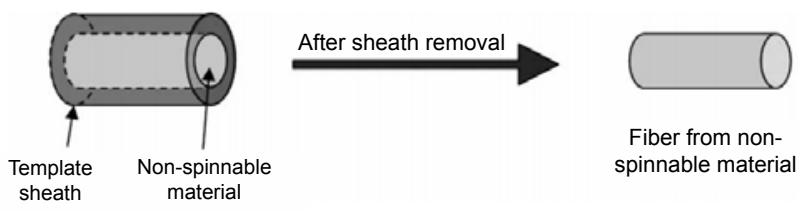

Figure 13: Schematic of fiber formation from non-electrospinnable material. 


\begin{tabular}{|c|c|c|c|c|c|}
\hline \multirow{2}{*}{$\begin{array}{c}\text { Sheath/core } \\
\text { polymers }\end{array}$} & \multicolumn{2}{|c|}{ Solvents } & \multirow{2}{*}{$\begin{array}{l}\text { Fiber dia }(\mathrm{nm}) \\
\text { Total (core) }\end{array}$} & \multirow{2}{*}{$\begin{array}{l}\text { Objective of } \\
\text { the study }\end{array}$} & \multirow[t]{2}{*}{ Reference } \\
\hline & Sheath & Core & & & \\
\hline $\begin{array}{l}\text { PEO/PEO } \\
\text { PEO/PSU }\end{array}$ & $\begin{array}{l}\text { Water + ethanol } \\
\text { Water + ethanol }\end{array}$ & $\begin{array}{c}\text { Water + ethanol } \\
\text { Chloroform }\end{array}$ & $\begin{array}{c}3000(2000) \\
60(40)\end{array}$ & $\begin{array}{l}\text { To demonstrate the } \\
\text { feasibility of the co-axial } \\
\text { electrospinning process }\end{array}$ & $\begin{array}{l}\text { Sun et al. } \\
2003 \text { [21] }\end{array}$ \\
\hline PCL/Gelatin & TFE & TFE & $\begin{array}{c}100 \text { to } 300 \\
(<100)\end{array}$ & $\begin{array}{l}\text { To demonstrate core-sheath } \\
\text { fiber formation using } \\
\text { bio-degradable materials }\end{array}$ & $\begin{array}{c}\text { Zhang et al. } \\
2004 \text { [8] }\end{array}$ \\
\hline PCL/Gelatin & TFE & TFE & $\begin{array}{l}200 \text { to } 500 \\
(61 \text { to } 180)\end{array}$ & $\begin{array}{l}\text { To improve mechanical } \\
\text { performance of the nano fiber mat }\end{array}$ & $\begin{array}{l}\text { Huang et al. } \\
2005[22]\end{array}$ \\
\hline Collagen/PCL & HFIP & TFE & 385 (321) & $\begin{array}{l}\text { To improve surface bio-compatibility of the nano } \\
\text { fibers for tissue engineering application }\end{array}$ & $\begin{array}{l}\text { Zhang et al. } \\
2005[10]\end{array}$ \\
\hline PVP/PLA & $\begin{array}{l}\text { DMF + } \\
\text { ethanol }\end{array}$ & $\begin{array}{c}\text { DMF + } \\
\text { acetone }\end{array}$ & $\begin{array}{l}400 \text { to } 500 \\
(200 \text { to } 300)\end{array}$ & $\begin{array}{l}\text { To prepare biodegradable composite nanofiber } \\
\text { structure for possible controlled particle release } \\
\text { application (e.g. drug delivery) }\end{array}$ & $\begin{array}{l}\text { Sun et al. } \\
2006 \text { [39] }\end{array}$ \\
\hline
\end{tabular}

Table 2: List of studies using co-axial electrospinning to prepare core-shell nanofibers.

material to form fibers even if the latter was not capable of forming fibers by itself in single jet electrospinning. Pure fibers of these materials could then be obtained after selectively removing the sheath using a suitable solvent (Figure 14).

Some materials are rendered non-electrospinnable due to their low molecular weight, limited solubility, unsuitable molecular arrangement, or lack of required viscoelastic properties [20,21,25,33]. Conductive polymers, metals, or some natural polymers that cannot form fibers by themselves for the reasons mentioned could therefore be spun using this approach and find unique applications in the fields of electronics, optics, and biomedical. The obvious requirement for this approach, however, is that the sheath polymer is effectively electrospinnable by itself and should possess appropriate viscosity [20]. Table 3 lists the studies reported using this approach.

In the very first study conducted by Sun et al. [21], the researchers demonstrated the feasibility of the approach by producing fibers from a polymer poly(dodecylthiopene). (PDT) and a metal salt (palladium (II) diacetate $\left.\left(\mathrm{Pd}(\mathrm{OAc})_{2}\right)\right)$ [11] neither of which could form fibers by themselves. In the subsequent study by Yu et al. [12], it was proposed that using the technique of co-axial electrospinning, ultra-fine fibers could be produced using a highly dilute solution of an electrospinnable polymer in the core, which would otherwise produce droplets due to jet breakup when spun alone. This concept was proved by using dilute solutions of PAN ( 3 and 5 wt.\%) in the core wrapped by PANco-PS. Removal of the sheath after electrospinning resulted in very fine diameter PAN fibers (100 nm or less) with narrow and unimodal distribution [20]. Recently, in a more detailed study of silk and PEO (core/sheath) system with water as the solvent for both polymers, it was reported that the crystallized silk fibers (converted from the random coil, silk I, conformation to stable $\beta$-sheet, silk II, structure) could be produced after annealing at high humidity $\left(90 \% \mathrm{RH}\right.$ at $\left.25^{\circ} \mathrm{C}\right)$ and subsequent water extraction of the PEO sheath [32]. The authors also studied the effect of the sheath and the core flow rates to obtain fibers with different sheath and core dimensions. They observed, as one would expect, that the sizes increased directly with the flow rates [32].

Li et al. [33] adopted the same approach to prepare nanofibers using conjugated polymers having conducting properties for use in electronics and semiconductor applications. The model polymers used by the authors were poly[2-methoxy-5-(2-ethylhexy-loxy)-1,4phenylenevinylene] (MEH-PPV) and poly(3-hexylthiopene) (PHT) which could not be electrospun into fibers due to limited solubility [33]. The sheath polymer chosen was PVP which was later extracted using ethanol.

From these studies, it appears that this novel approach for making nanofibers from otherwise non-spinnable polymers could be used for a wide variety of materials. However, little has been published that sheds light on the actual properties, especially mechanical, of such fibers.

Preparation of hollow nanofibers: Another unique application of the co-axial electrospinning process has been in developing hollow nanofibers or nanotubes from ceramic and ceramic-polymer composites that are otherwise commonly prepared using tedious processes. The latter include self-assembly and template synthesis, which are the so-called "bottom up" techniques in nanotechnology [40,41]. These techniques require manipulation of atoms and molecules to assemble them in desirable structures for obtaining a product that is at least an order of magnitude bigger in size than the molecules themselves.

The concept of making hollow fibers at nano level is, in fact, opposite to that illustrated in figure 14 . Here, the core is selectively removed, instead of the sheath, from the assembly to obtain hollow nanofibers (Figure 15).

The idea of producing nanotubes using the co-axial electrospinning was first reported, independently, by $\mathrm{Li}$ and $\mathrm{Xia}$ [5] and Loscertales et al. [40]. Both produced ceramic and composite hollow nanofibers. Non-polymeric liquid was employed as the core solution which was either heavy mineral oil as used by Li and Xia [5] or olive oil or glycerin as used by Loscertales et al. [14]. A combination of polymer PVP and a ceramic precursor $\mathrm{Ti}(\mathrm{OiPr})_{4}$, dissolved in ethanol, as the sheath solution and heavy mineral oil as the core. After hydrolysis of the precursor, simply by a prolonged exposure to air, the oil was extracted using octane. The structure was further calcinated to obtain pure titania nanotubes (Figure 16). According to the authors, the dimensions of the hollow nanofibers, in terms of the inner diameter and the wall thickness, can simply be varied by changing the feeding rate of the oil. The dimensions of the hollow fibers obtained were: inner diameter 200$370 \mathrm{~nm}$, and wall thickness 20-50 nm. Loscertales et al. [14] pre-pared the silica nanotubes in a similar way by using tetraethyl orthosilicate (TEOS) as the sheath.

Li et al. (2001) [31] further showed that the ceramic nanotubes could be functionalized using various dopes or particles incorporated in the oil while electrospinning, which tended to bond to the inner surface of the tube and be retained even after the removal of the oil core.

Wang et al. (2006) [24] recently reported the formation of nanochannels ( $60 \mathrm{~nm}$ or less) in silica nanofibers by this technique. They used spin-on glass (SOG) and a PVP mixture in the sheath and motor oil in the core. After electrospinning, the structure was calcinated to remove PVP and motor oil and to form crosslinked $\mathrm{SiO}_{2}$ wall. 


\begin{tabular}{|c|c|c|c|c|}
\hline \multirow{2}{*}{$\begin{array}{l}\text { Sheath/core } \\
\text { materials }\end{array}$} & \multicolumn{2}{|c|}{ Solvents } & \multirow{2}{*}{$\begin{array}{l}\text { Fiber diameters }(\mathrm{nm}) \\
\text { Total (core) }\end{array}$} & \multirow[t]{2}{*}{ Reference } \\
\hline & Sheath & Core & & \\
\hline $\begin{array}{l}\text { PEO/PDT } \\
\text { PLA/Pd(OAc) }{ }_{2}\end{array}$ & $\begin{array}{l}\text { Chloroform } \\
\text { Chloroform }\end{array}$ & $\begin{array}{l}\text { Chloroform } \\
\text { THF }\end{array}$ & $\begin{array}{l}1000(200) \\
500(60)\end{array}$ & $\begin{array}{l}\text { Sun et al. } \\
2003 \text { [21] }\end{array}$ \\
\hline $\begin{array}{l}\text { PVA/PAni } \\
\text { PEO/Bombyx } \\
\text { mori silk } \\
\text { PAN-co-PS/ } \\
\text { PAN }\end{array}$ & $\begin{array}{l}\text { Water } \\
\text { Water } \\
\text { DMF }\end{array}$ & $\begin{array}{l}\text { Water } \\
\text { Water } \\
\text { DMF }\end{array}$ & $\begin{array}{l}310(120) \\
800(600) \\
500 \text { to } 2000 \\
(65 \text { to } 105)\end{array}$ & $\begin{array}{l}\text { Yu et al. } \\
2004 \text { [20] }\end{array}$ \\
\hline $\begin{array}{l}\text { PEO/ Bombyx } \\
\text { mori silk }\end{array}$ & Water & Water & $\begin{array}{l}680 \text { to } 790 \\
(170 \text { to } 660)\end{array}$ & $\begin{array}{l}\text { Wang et al. } \\
2006 \text { [32] }\end{array}$ \\
\hline PVP/MEH-PPV & $\begin{array}{l}\text { Water + } \\
\text { ethanol }\end{array}$ & Chloroform & $\begin{array}{l}150 \text { to } 500 \\
\text { (Core ribbon like with } \\
\text { thickness } 30 \mathrm{~nm} \text { ) }\end{array}$ & $\begin{array}{l}\text { Li et al. } \\
2004 \text { [33] }\end{array}$ \\
\hline
\end{tabular}

Table 3: List of studies using co-axial electrospinning to form fibers from non-electrospinnable materials.

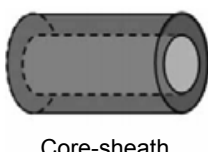
nanofiber
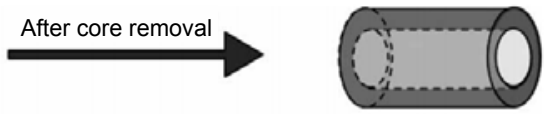

Hollow fiber
Figure 14: Schematic of hollow fiber formation.

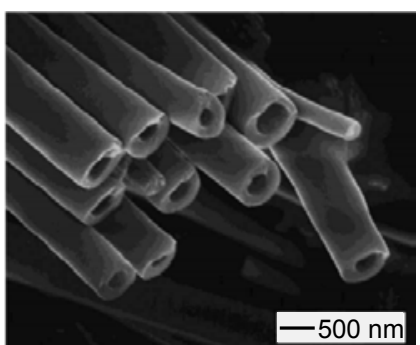

Figure 15: Hollow composite nanofibers prepared by co-axial electrospinning technique [26].
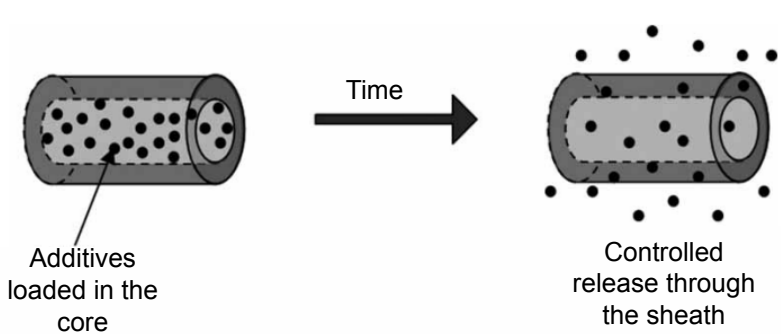

Figure 16: Schematic of micro-encapsulation of additives and controlled release.

$\mathrm{Li}$ and $\mathrm{Xia}[13]$ stated that the presence of ceramic precursor in the polymer solution was essential not only to stabilize the compound jet and entrain the oil uniformly but also to form rigid walls necessary to maintain the tubular shape. Loscertales et al. [40], along the same lines, suggested that the sheath should withstand the capillary forces during the core extraction in order to maintain the hollow fiber morphology. Pure polymers lack the degree of hardness required in the wall and tend to collapse after the removal of the core and therefore, preparation of nanotubes comprised of pure polymers has not yet been reported [41]. Li and Xia (2004) [26] further stressed that the use of immiscible solutions was necessary to form continuous hollow fibers with a smooth interior surface. When a miscible solution of PVP was used in the core, instead of the oil, they observed that no hollow structure was present after removing the core polymer which indicated no core- sheath fiber formation due to mixing of the two polymer solutions during the spinning process [26].

Fibers containing micro-encapsulated compounds: The major application of co-axial electrospinning may be in micro-encapsulation of the compounds for providing novel functional and aesthetic behaviors. Such products can be expected to be most useful in applications such as gene therapy, drug delivery, tissue engineering, and even odor absorption and scent release materials. Although the basic concept of this approach overlaps with those stated in the first two approaches, it can be distinguished largely in terms of the materials that are encapsulated, which range from liquids, through biological objects to solids, the latter of any shape, including spherical. Table 4 gives a summary of the materials used in different studies and lists the authors who performed the work.

Loading of the drugs in nanofibers using the conventional single fluid electrospinning has been reported earlier; however, the approach suffered from the fact that the release rate was very high initially and decreased greatly with time [40]. Therefore, the ideal structure thought of was a core containing the drug particles and an additional barrier surrounding it, for sustained release, obtained with co-axial electrospinning (Figure 16).

The practicality of the approach was demonstrated by Jiang et al. [41] in a study using PCL sheath and bovine serum albumin (BSA) or lysozyme doped poly(ethylene glycol) (PEG) core. The authors concluded that the structure and the functionality of the released proteins were unaltered. In a more refined study, the same authors later showed that the release rate of the proteins encapsulated in the core could be tuned simply by altering the chemical composition of the sheath [42]. They used a blend of PCL and PEG in the sheath and BSA or lysozyme added dextran in the core. It was shown that the release rate depended on the fraction of PEG in the sheath which, being soluble in water, formed pores in the PCL sheath and provided passage for the release of the protein [42].

Encapsulation of fluorescein isothiocyanate-Conjugated BSA (FitcBSA) in the core with PEG, wrapped by PCL sheath, has also been reported recently by Zhang et al. (2006) [43]. In this study, a comparison was made between the protein release profiles from the two composite fibers, one prepared by the co-axial process, and the other prepared via the single fluid electrospinning process. The results clearly showed that a better sustained release were achieved using the protein encapsulated co-axial fibers. Similarly, successful encapsulation of the drug, tetracycline hydrochloride (TCH), was presented by He et al. [29] using PLLA sheath. In this work, a dilute solution of PLLA was used for the core to achieve uniform dispersion of the drug molecules. The authors found that the release rate of the drug could be controlled by varying the sheath thickness which could be easily changed by changing the concentration of PLLA in the sheath solution [29].

The concept of encapsulation of additives was not limited to drug delivery and controlled release applications but could also be utilized in altering the physical or chemical properties of the resultant fibers. Song et al. [44] proposed the idea of encapsulating magnetic particles in nanofibers to obtain a nonwoven mat that had magnetic properties and could be used in a host of products, including smart materials. As a model, the iron-platinum (FePt) nanoparticles were dispersed in hexane, stabilized using surfactants, and the dispersion used as the core 
Citation: Elahi MF, Lu W, Guoping G, Khan F (2013) Core-shell Fibers for Biomedical Applications-A Review. J Bioengineer \& Biomedical Sci 3: 121. doi:10.4172/2155-9538.1000121

Page 9 of 14

\begin{tabular}{|c|c|c|c|c|c|}
\hline \multirow{2}{*}{\multicolumn{2}{|c|}{$\begin{array}{c}\text { Encapsulated material and core polymer } \\
\text { Sheath material }\end{array}$}} & \multicolumn{2}{|c|}{ Solvents } & \multirow{2}{*}{$\begin{array}{l}\text { Fiber diameters }(\mathrm{nm}) \\
\text { Total (core) }\end{array}$} & \multirow{3}{*}{\begin{tabular}{|r|} 
References \\
Jiang et al. 2005 [41]
\end{tabular}} \\
\hline & & \multirow{2}{*}{\begin{tabular}{|c|} 
Sheath \\
DMF+chlorofom
\end{tabular}} & \multirow{2}{*}{ Core } & & \\
\hline Proteins-BSA & PCL & & & 550 to 775 (80 to 311$)$ & \\
\hline $\begin{array}{l}\text { Lysozyme with PEG } \\
\text { Proteins- BSA }\end{array}$ & $P C L+P E G$ & DMF+chloroform & $\begin{array}{l}\text { DMF+ } \\
\text { chloroform }\end{array}$ & 2000 to 5700 & Jiang et al. 2006 [42] \\
\hline $\begin{array}{l}\text { Lysozyme with dextran } \\
\text { protein-FitcBSA with PEG }\end{array}$ & PCL & TFE & Water & $\begin{array}{l}\text { (core-not reported) } \\
270 \text { to } 380 \text { (100 to } 200)\end{array}$ & Zhang et al. 2006 [43] \\
\hline Drug- TCH with PLLA & PLLA & Chloroform+acetone & Methanol +chloroform & 150 to 3000 (60 to 215$)$ & He et al. 2006 [29] \\
\hline $\begin{array}{l}\text { Magnetic nanoparticles- } \\
\text { FePt }\end{array}$ & PCL & TFE & $\begin{array}{l}\text { Dispersion of } \\
\text { FePt in hexane }\end{array}$ & 100 to 600 (50 to 75$)$ & Song et al. 2006 [44] \\
\hline $\begin{array}{l}\text { Phase change materials-octadec- } \\
\text { ane, hexadecane \& eicosane }\end{array}$ & $\begin{array}{l}\mathrm{PVP} / \mathrm{Ti}(\mathrm{OiPr})_{4} \\
\text { composite }\end{array}$ & $\begin{array}{l}\text { Acetic acid+ } \\
\text { ethanol }\end{array}$ & $\begin{array}{l}\text { None-core in } \\
\text { melt form }\end{array}$ & $\begin{array}{l}100 \text { to } 150 \text { (core-not } \\
\text { continuous, broke-up into droplets) }\end{array}$ & $\begin{array}{l}\text { McCann et al. } 2006 \text { [23] } \\
\text { Diaz et al. [27] }\end{array}$ \\
\hline Oil & PVP & DMF & None & $\begin{array}{l}\text { Beaded fibers core liquid in beads } \\
\text { (size } 2 \text { to } 10 \mathrm{~mm} \text { ), total fiber diam-eter } \\
\text { between the beads is } 1 \text { to } 1.5 \mu \mathrm{m}\end{array}$ & Diaz et al. [27] \\
\hline Cell suspension & $\begin{array}{l}\text { Medical grade } \\
\text { PDMS }\end{array}$ & Not reported & & Not reported & $\begin{array}{l}\text { Townsend-Nicholson \& Jayas- } \\
\text { inghe [28] }\end{array}$ \\
\hline
\end{tabular}

Table 4: List of studies using co-axial electrospinning to achieve micro-encapsulation.

solution (Figure 17). The authors showed that the prepared structure exhibited magnetic behavior, as demonstrated by a typical hysteresis loop obtained using an alternating gradient magnetometer [44].

McCann et al. [23] recently introduced an approach that combines the process of melt electrospinning with that of the co-axial electrospinning in an effort to encapsulate the phase change materials (PCMs) into polymer or composite sheath. PCM can help stabilize the temperature near its melting point as the material changes the state from a solid to a liquid or vice versa and the enthalpy of fusion causes absorption or release of the thermal energy, and therefore the nanofibers produced using such a material could be used in thermal insulation applications [23]. The researchers used three PCMs, octadecane, hexadecane, and eicosane, in melt forms as core solutions and demonstrated temperature stabilization at three different points i.e. 17,30 , and $37^{\circ} \mathrm{C}$, respectively.

Two of the most recent studies reported have shown the potential of taking the approach of encapsulation of materials by co-axial electrospinning to the next level of success. The work by Diaz et al. [27] described encapsulation of hydrophobic liquids in hydrophilic polymer nanofibers for potential biomedical applications, such as in delivery of hydrophobic drugs using hydrophilic sheaths. The concept was demonstrated using poly (vinyl pyrrolidone) (PVP) as the sheath and oil as the core. They obtained a beaded fiber structure with the oil contained in the periodically separated beads (Figure 18).

The second study by Townsend-Nicholson and Jayasinghe [28] gave the details of an approach in which living organisms such as cells could be entrained into a biocompatible polymer to construct a "biologically active scaffold." A biosuspension of cells was used as the core and the polymer solution of poly(dimethyl siloxane) (PDMS) was employed as the sheath (Figure 19). During co-axial electrospinning, the cell suspension formed clumps along the length of the fiber, similar to the structure obtained above. The cell viability assays after the electrospinning procedure demonstrated the full functionality of the cells [28].

The results illustrate that the electric charges present on the surface of the droplet during electrospinning did not penetrate and adversely affect the interior. Thus, the process could be used in encapsulating biological objects for developing biologically active products.
It may be mentioned that for fiber formation from nonelectrospinnable solid materials, the high viscosity requirement for the polymer sheath is justified. However, studies by TownsendNicholson and Jayasinghe [23], Diaz et al. [27], and McCann et al. [28] for the encapsulation of liquid cores, indicate that this criterion alone is insufficient as the core jet tends to break-up and produce beads along the fiber length. To overcome this problem, Li and Xia [26] had suggested that some degree of robustness was required in the sheath material which was achieved by adding a ceramic precursor.

In a more recent study, McCann et al. [23] found that even after using the polymer and ceramic composite as the sheath component $\left(\mathrm{PVP} / \mathrm{TiO}_{2}\right)$ the liquid (melt) in the core tended to break-up into droplets and the reason, speculated by the authors, was the low viscosity of the core. Therefore, it may be concluded that a certain minimum viscosity of the liquid to be encapsulated as the core would also be required in order to prevent the jet break-up. Certainly, more studies are needed that identify and quantify the requirements of the properties of the sheath solution and the core liquids for uniform encapsulation of the latter.

\section{Core-shell fibers produced by emulsion electrospinning}

Emulsion electrospinning is similar to the normal solution electrospinning, except that the solution is replaced by an emulsion. Jets are generated from the emulsion liquid and stretched into ultrafine fibers. The dispersed drop in the emulsion turns into the core of the electrospun fibers, and the continuous matrix becomes the shell. The water-in-oil (W/O) emulsion electrospinning is particularly used for encapsulating hydrophilic drugs or bioactive molecules inside the core of electrospun core/shell fibers to avoid burst release and prolong the release time [45-55].

$\mathrm{Xu}$ et al. [45] described, a water-soluble polymer such as PEO and an amphiphilic polymer such as poly(ethylene glycol)-poly(L-lactic acid) (PEG-PLA) diblock copolymer were generally incorporated into the W/O emulsion, and a proper emulsifying agent was usually used as a surfactant to lower the surface tension [46]. During electrospinning, the aqueous drops were stretched into elliptical shapes in the axial direction of fibers and gave rise to the continuous core.

Because the organic solvent evaporated relatively faster than distilled water and the viscosity of the organic matrix increased more rapidly 


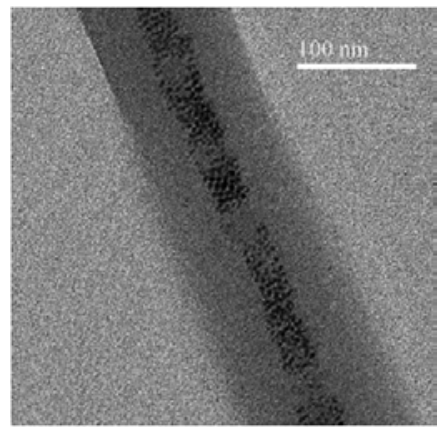

Figure 17: Encapsulation of magnetic particles into polymeric nanofibers [44].



Figure 18: Encapsulation of liquid into polymeric fibers [27].

than that of the droplets, the outer layer of the fiber solidified more rapidly than that of the inner core. The viscosity difference between the drop and the matrix resulted in the inward movement of drops and followed their mergence. Eventually, the water-soluble polymer became the core and the hydrophobic or amphiphilic polymer transformed as the shell of the core-shell fibers via emulsion electrospinning [46].

In addition to $\mathrm{W} / \mathrm{O}$ emulsion electrospinning, another kind of oil-in-water $(\mathrm{O} / \mathrm{W})$ emulsion electrospinning was also investigated by Angeles et al., showing different phenomena [56]. Xu et al. [45] observed emulsion drops were broken up into smaller droplets during electrospinning instead of forming the continuous core $[45,46]$. When the organic solvent evaporated and the viscosity of the drop phase increased more sharply than that of the matrix, drops did not further deform and break up readily, so that solid particles or liquid drops were encapsulated in the electrospun fibers.

Emulsion stability in electrospinning: For water-drug delivery by W/O emulsion electrospinning, a stable emulsion staying for several hours would avoid drug precipitation. If the emulsion is not stable enough, the drug may agglomerate and locate on the surface of electrospun fibers, resulting in a burst drug-release [45]. Therefore, a water-soluble polymer such as PEO is added to increase the drop size as well as the drop viscosity to avoid drug agglomeration $[45,46]$. As a special core of $\mathrm{W} / \mathrm{O}$ emulsion electrospinning, a drug suspended in a polymer solution with a surfactant but lack of a water-soluble polymer could also be electrospun into fibers. Therefore, emulsion electrospinning usually requires an adequate surfactant, a suitable solvent and a ratio of water for stabilizing the emulsion (Figure 20).

In emulsion electrospinning, the drop phase is required not to be too viscous for deformation and encapsulation. In the W/O case, the water phase usually has a relatively lower viscosity than the oily phase because of the lower evaporation rate of water. Thus, the oily matrix tends to be more viscous to form the shell, while the aqueous drops are forced to stretch and coalesce in the center. In the O/W case, on the contrary, if the oily drops have a relatively larger value of viscosity, deformation is problematic, resulting in incomplete coalescence and further incomplete encapsulation of drugs [56]. Therefore, the two cases follow the common interpretation that the proper viscosity of the drop phase and the stable emulsion are critical for emulsion electrospinning.

\section{Biomedical Applications of Core-shell Fibrous Membranes}

Ultrafine core-shell fibers in the form of nonwoven membranes produced by coaxial or emulsion electrospinning have been applied as tissue engineering scaffolds, drug release systems, wound dressings, and others [45-81]. Advantages and limitations of this kind of fibrous membranes are described in the following paragraphs.

\section{Drug delivery vehicles}

Core/shell structured fibers with different characteristic materials could meet particular requirements, such as sustained release of drugs, growth factors, peptides, plasmid DNA and other biomolecules for organ and/or tissue regeneration.

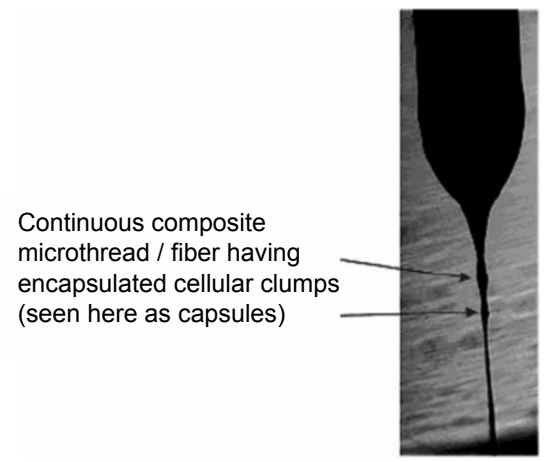

Figure 19: Encapsulation of living cells into polymeric fibers [28]

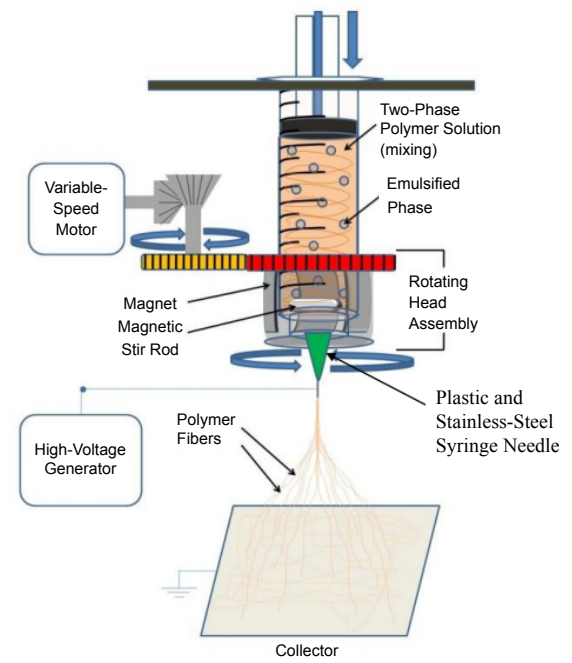

Figure 20: Emulsion electrospinning for producing dome-shaped structures within I-tyrosine polyurethane scaffolds for gene delivery, master thesis, The University of Akron, 2010. 
Applying co-axial electrospinning process: Applying core-shell structured fibers as carriers, delivery of drugs could be controlled in a sustained manner. For example, Huang et al. [57] used PCL as the shell and two drugs, resveratrol (an antioxidant) in ethanol and gentamycin sulfate (an antibiotic) in water, as the cores to prepare core-shell fibers by coaxial electrospinning, and drug release profiles exhibited sustained characteristics without the burst phenomenon. It was indicated that the core-shell ultrafine fibers via coaxial electrospinning could be conveniently applied as reservoir-like drug delivery devices.

The diameter of the ultrafine fibers had a significant effect on the physicochemical properties and the sustained drug release behaviors of coaxial electrospun poly(L-lactide) (PLLA) fibers containing a model drug tetracycline hydro chloride in the core to be used as the suture [67]. The in vitro release study suggested that the suture thread made from the core/shell fibers by coaxial electrospinning could suppress the initial burst release and provide a sustained drug release [64].

Jiang et al. [58] found that the released lysozyme (a model protein) from core/shell fibers of PCL as the shell was produced through coaxial electrospinning could maintain its structure and bioactivity. A small molecule PEG was added to the PCL shell to further finely modulate the release behavior of proteins. With the increase of the flow rate of the inner solution, there was an associated increase in the loading efficiency and an accelerated release rate of proteins [68].

Coaxial electrospinning bears limitations in selection of proper solvents and process parameters. The drug release often presents a $20 \%-30 \%$ initial burst because of the ineluctable defect of some coreshell fibers. Therefore, improvement of coaxial electrospinning would be required for more extensive applications.

Applying emulsion electrospinning process: Emulsion electrospinning is a relatively facile technique, and may provide a better encapsulation for the sustained release of biomedical additives. If the biomolecule is active, coaxial electrospinning is more suitable, despite the defects of core/shell fiber structures possibly exist. Improvement of coaxial or emulsion electrospinning can depend on introduction of micro- or nanoparticles.The significant application of emulsion electrospinning was to deliver water-soluble drugs or biomolecules in the $\mathrm{W} / \mathrm{O}$ emulsion.

Jing et al. [58] first proposed a three-stage diffusion-controlled mechanism based on the release behavior of hydrophilic doxorubicin hydrochloride (DOX) from PEG-PLLA diblock copolymer fibers prepared by emulsion electrospinning $[64,66]$. Both hydrophobic paclitaxel (PTX) and hydrophilic DOX were loaded into ultrafine PEGPLA fibers together by emulsion electrospinning, and it was found that the release rate of PTX was accelerated by DOX [48].

Rhodamine B and BSA was incorporated into PLCL fibers by emulsion electrospinning, and the release profile showed a sustained manner controlled mostly by diffusion and degradation of fibers. It indicated that the electrospun fibrous membranes were expected to carry dual hydrophilic and/or hydrophobic drugs and proteins for biomedical applications or pharmaceutical devices [49].

By encapsulation of dispersed micro- or nanoparticles, multi-drugs could also be loaded in ultrafine fibers via emulsion electrospinning. Jo et al. electrospun a PCL solution containing poly( $\mathrm{N}$-isopropyl acrylamide) microgel particles or PMMA colloids by emulsion electrospinning for a separately controlled release of multiple drugs by adjusting the physicochemical properties of the colloids [69]. An improvement research was made by Qi et al. [70] by incorporating Calcium alginate microspheres as reservoirs for hydrophilic drugs in electrospun PLLA fibers. With BSA loaded into the microspheres, the bead-in-string structure achieved prolonged release profiles and a lower burst release than that from the naked Ca-alginate microsphere [70]. Nie et al. [71] loaded recombinant human bone morphogenetic protein-2 (BMP-2) into PLGA fibers by introduction of hydroxylapatite (HAp) nanoparticles for bone tissue regeneration, and found that the sustained release of BMP-2 was accelerated with increasing the HAp amount to enhance the attachment of marrow derived mesenchymal stem cells.

The influence of surfactant distribution in emulsion electrospun fibers on drug release profiles has drawn much attention. Li et al. found that some of the surfactant sorbitan monooleate (Span 80) existed on the surface of the PLCL fibers obtained by emulsion electrospinning, which led to higher hydrophilicity of the electrospun membranes [53]. Liao et al. also pointed out the similar phenomenon by a comparative investigation of electrospun membranes prepared from three different PLGA solutions, a W/O emulsion consisting of PLGA, Span 80 and Rhodamine B in chloroform/DMF/water, and PLGA solutions with or without Span 80 [54]. The surfactant on the fiber surface could possibly hinder cell attachment in the later on applications.

\section{Core-shell fibers in tissue engineering scaffolds}

So many studies showed that the core-shell fibrous membranes produced via coaxial or emulsion electrospinning could be used as scaffolds in tissue engineering. Improvement of these electrospinning methods for controlled release systems suggested the tremendous potentials of electrospinning fibers used as tissue engineering scaffolds.

In tissue engineering a suitable scaffold is required to provide a cell growth template and mechanical support. In addition to biocompatibility and biodegradability, it is necessary for scaffolds to carry bioactive signals such as growth factors, genes, DNA and other frail biomolecules to stimulate cell proliferation in a sustained manner. Many model proteins and biomolecules encapsulated in core-shell fibers were investigated. Cells were also tried to be electrospun in fibers via coaxial electrospinning $[65,72]$

Yi et al. [73] formed biodegradable poly(glycerol sebacate) (PGS)/ PLLA composite fibers by coaxial electrospinning from 15\% PGS/5\% PLLA and 10\% PLLA in 1,1,1,3,3,3-hexafluoropropanol as the inner and outer solutions, respectively, and the fibrous scaffold exhibited good compatibility with human microvascular endothelial cells.

In another research, electrospun core-shell PVP/PLCL membranes were obtained for skin dressings [74], and platelet derived growth factor-bb (PDGF-bb) was loaded into core/shell DEX/PLCL fibers for blood vessel scaffolds by coaxial electrospinning [75]. Similarly, Liao et al. encapsulated PDGF-bb into the core of PCL fibers via coaxial electrospinning, and cell proliferation was tested for ensuring the preservation of bioactivity [76]. For immobilizing vascular endothelial growth factor (VEGF), gelatin was cationized by $\mathrm{N}, \mathrm{N}$-dimethyl ethylenediamine, and thus the core/shell PCL/gelatin fibers prepared via coaxial electrospinning could adsorb heparin. It was revealed that sustained release of bioactive VEGF could be achieved for more than 15 days [59].

Similar core-shell fiber carriers encapsulating growth factors or DNA for tissue engineering were prepared via emulsion electrospinning [50-52,55,70,71,77-79]. Yang et al. [50] focused on the effect of the fiber 
structure on the release profiles and structural stability of encapsulated proteins. BSA and lysozyme were encapsulated in core-shell structured PLA ultrafine fibers which could serve as a promising scaffold for sustainable, controllable, and effective release of bioactive proteins in tissue engineering and other applications [50,51]. In a research, PEG-PLLA ultrafine fibers encapsulating proteinase $\mathrm{K}$ with core/shell structure were obtained by emulsion electrospinning. The accelerated PEG-PLLA degradation showed that released proteinase $\mathrm{K}$ kept its activity [55]. In Chew's report, human P-nerve growth factor (NGF) stabilized with BSA was encapsulated in a copolymer of e-caprolactone and ethyl ethylene phosphate by emulsion electrospinning and sustained release of NGF was achieved for at least 3 months [52].

For skin dressing and blood vessel scaffolds, biodegradable coreshell fibrous scaffolds with PCL were prepared as the core and gelatin as the shell by coaxial electrospinning [33]. The crosslinked core/shell fibrous scaffold was non-toxic and capable of supporting fibroblast adhesion and proliferation [61]. Core/shell PCL/gelatin fibers via coaxial electrospinning were also prepared by Huang et al. [50]. In order to improve the mechanical strength of the hydrated zein meshes, Jiang et al. [80] prepared core/shell structure nanofibrous membranes with PCL as the core material and zein as the shell by coaxial electrospinning. PCL and collagen were also selected as the core scaffold material and the shell coating, respectively [60]. In the above studies, PCL holds good mechanical properties, and gelatin or collagen regulates cellscaffold interactions of core/shell composite fibers in tissue engineering applications.

Coaxial electrospinning was utilized to obtain required- shape for different mechanical properties. Chen et al. [66] achieved coreshell fibers to introduce a tight nanocoil (nanospring) configurations via a differential shrinkage of a parallel arrangement of a flexible thermoplastic elastomer component and a rigid thermoplastic component by coaxial electrospinning for tissue engineering. Wang et al. [81] annealed silk/PEO fibers, and extracted PEO to obtain silk fibers with smaller diameters.

\section{Conclusion}

Most of these human organs deposited on fibrous structures with the fibril/fiber size realigning from nanometer to millimeter scale. So nanofiber has now been extensively used to mimic these natural tissue matrixes.

The unique core-shell structure offers a number of potential benefits. For example, the core materials should provide certain properties required by the tissue to be repaired, while the shell materials could be tailored to provide or endow additional properties, such as biocompatibility or hydrophilic properties. The major advantage of this core-shell nanostructure is the potential to obtain a combination of properties of different kind of materials.

Coaxial electrospinning could satisfy required mechanical properties by adjusting the materials and operating parameters and embed living cells into nanofiber scaffolds, especially hydrophilic growth factors and genes could reach sustained release and retain their bioactivities resulting from the core-shell structure of fibers.

In addition to the release profile of biomolecules, mechanical properties and biocompatibility could also be enhanced via coaxial electrospinning. Although core-shell nanofibers are synthesized using the coaxial electrospinning technique, the porosity of core shell fiber networks has not been fully explored. The physical and chemical of elec-trospinning systems play an important role in controlling the morphologies of polymeric nanofibers. Furthermore, ambient parameters regulate phase separation and solvent evaporation processes that can control the porosity of fiber networks.

\section{References}

1. Liu T, Burger C, Chu B (2003) Nanofabrication in polymer matrices. Prog Polym Sci 28: 5-26.

2. Zhang S (2003) Fabrication of novel biomaterials through molecular selfassembly. Nat Biotechnol 21: 1171-1178.

3. Smith LA, Ma PX (2004) Nano-fibrous scaffolds for tissue engineering. Colloids Surf B Biointerfaces 39: 125-131.

4. Xie XN, Chung HJ, Sow $\mathrm{CH}$, Wee ATS (2006) Nanoscale materials patterning and engineering by atomic force microscopy nanolithography. Mat Sci Eng R. 54: $1-48$.

5. Li D, Xia Y (2004) Electrospinning of nanofibers: reinventing the wheel? Adv Mater 16:1151-1170.

6. Huang ZM, Zhang YZ, Kotaki M, Ramakrishna S (2003) A review on polymer nanofibers by electrospinning and their applications in nanocomposites. Compos Sci Technol 63: 2223-2253.

7. Loscertales IG, Barrero A, Guerrero I, Cortijo R, Marquez M, et al. (2002) Micro/ nano encapsulation via electrified coaxial liquid jets. Science 295: 1695-1698.

8. Zhang Y, Huang ZM, Xu X, Lim CT, Ramakrishna S (2004) Preparation of core-shell structured PCL-r-Gelatin bi-component nanofibers by co-axial electrospinning Chem Mater. 16: 3406-3409.

9. Weinberg S, King MW. Medical Fibers and Biotextiles. In: Biomaterials Science (2ndedn), Ratner BD, Hoffman, AS, Schoen FF, Lemons JE, Edn. Elsevier Academic Press, San Diego 86-100.

10. Zhang YZ, Venugopal J, Huang ZM, Lim CT, Ramakrishna S (2005) Characterization of the surface biocompatibility of the electrospun PCLcollagen nanofibers using fibroblasts. Biomacromolecules 6: 2583-2589.

11. Barnes CP, Sell SA, Boland ED, Simpson DG, Bowlin GL (2007) Nanofiber technology: designing the next generation of tissue engineering scaffolds. Adv Drug Deliv Rev 59: 1413-1433.

12. Boland ED, Espy PG, Bowlin GL (2004) Tissue engineering scaffolds. In: Wnek G, Bowlin G, editors. Encyclopedia of biomaterials and biomedical engineering. New York, Marcel Dekker 1-9.

13. Farach MC, Wagner RC, Kiick KL (2007) Extracellular matrix: structure, function, and applications to tissue engineering. In: Fisher JP, Mikos AG, Bronzino JD, editors. Tissue engineering. Boca Raton: CRC Press 3: 1-22.

14. Martins GM. (1997) The dynamics of cell-ECM interactions with implications for tissue engineering. In: Principles of tissue engineering, Lanza R, Langer $\mathrm{R}$ Chick W, (ed.), Georgetown 23-46.

15. Simpson DG, Bowlin GL (2006) Tissue-engineering scaffolds: can we reengineer mother nature? Expert Rev Med Devices 3: 9-15

16. Jeong SI, Kim SY, Cho SK, Chong MS, Kim KS, et al. (2007) Tissue-engineered vascular grafts composed of marine collagen and PLGA fibers using pulsatile perfusion bioreactors. Biomaterials 28: 1115-1122.

17. Kim K, Yu M, Zong X, Chiu J, Fang D, et al. (2003) Control of degradation rate and hydrophilicity in electrospun non-woven poly(D,L-lactide) nanofiber scaffolds for biomedical applications. Biomaterials 24: 4977-4985.

18. Ishaug-Riley SL, Okun LE, Prado G, Applegate MA, Ratcliffe A (1999) Human articular chondrocyte adhesion and proliferation on synthetic biodegradable polymer films. Biomaterials 20: 2245-2256.

19. Thomson RC, Shung AK, Yaszemski MJ, Mikos AG (2000) Polymer scaffold processing. In: Lanza RP, Langer R, Vacanti J, editors. Principles of tissue engineering. New York: Academic Press 251-62.

20. Yu JH, Fridrikh SV, Rutledge GC (2004) Production of submicrometer diameter fibers by two-fluid electrospinning. Adv Mater 16: 1562-1566.

21. Sun Z, Zussman E, Yarin AL, Wendorff JH, Greiner A (2003) Compound coreshell polymer nanofibers by co-electrospinning. Adv Mater 15: 1929-1932. 
Citation: Elahi MF, Lu W, Guoping G, Khan F (2013) Core-shell Fibers for Biomedical Applications-A Review. J Bioengineer \& Biomedical Sci 3: 121. doi:10.4172/2155-9538.1000121

22. Huang ZM, Zhang Y, Ramakrishna S (2005) Double layered composite nanofibers and their mechanical performance. J Polym Sci Part B: Polym Phys 43: 2852-2861.

23. McCann JT, Marquez M, Xia Y (2006) Melt coaxial electrospinning: a versatile method for the encapsulation of solid materials and fabrication of phase change nanofibers. Nano Lett 6: 2868-2872.

24. Wang M, Jing N, Su CB, Kameoka J, Chou CK, et al. (2006) Electrospinning of silica nanochannels for single molecule detection. Appl Phys Lett 88: 1-3.

25. Greiner A, Wendorff JH, Yarin AL, Zussman E (2006) Biohybrid nanosystems with polymer nanofibers and nanotubes. Appl Microbiol Biotechnol 71: 387-393.

26. Li D, Xia Y (2004) Direct fabrication of composite and ceramic hollow nanofibers by electrospinning, Nano Lett 4: 933-938.

27. Diaz JE, Barrero A, Marquez M, Loscertales IG (2006) Controlled encapsulation of hydrophobic liquids in hydrophilic polymer nanofibers by co-electrospinning. Adv Funct Mater 16: 2110-2116.

28. Townsend-Nicholson A, Jayasinghe SN (2006) Cell electrospinning: a unique biotechnique for encapsulating living organisms for generating active biological microthreads/scaffolds. Biomacromolecules 7: 3364-3369.

29. He CL, Huang ZM, Han XJ, Liu L, Zhang HS, et al. (2006) Coaxial electrospun poly(L-lactic acid) ultrafine fibers for sustained drug delivery. J Macromol Sci. Part B: Phys 45: 515-524.

30. Sara A, Arvidson, Ka CW, Russell EG, Saad AK, et al. (2012) Structure, molecular orientation, and resultant mechanical properties in core/sheath poly(lactic acid)/polypropylene composites. Polymer 53: 791-800.

31. Li D, McCann JT, Xia Y (2005) Use of electrospinning to directly fabricate hollow nanofibers with functionalized inner and outer surfaces. Small 1: 83-86.

32. Wang M, Yu JH, Kaplan DL, Rutledge GC (2006) Production of submicron diameter silk fibers under benign processing conditions by two-fluid electrospinning. Macromol 39: 1102-1107.

33. Li D, Babel A, Jenekhe SA, Xia Y (2004) Nanofibers of conjugated polymers prepared by electrospinning with a two-capillary spinneret. Adv Mater 16: 2062 2066.

34. Moghe AK, Gluck JM, Gupta BS, King MW (2005) Electrospun Bicomponent Fibers for Soft Tissue Engineering: Book of Abstracts, The Fiber Society Fall 2005 Annual Meeting and Technical Conference, Newark NJ, USA 73-74.

35. Larsen G, Spretz R, Velarde Ortiz R. (2004) Use of coaxial gas jackets to stabilize Taylor cones of volatile solutions and to induce particle-to-fiber transitions. Adv Mater 16: 166-169.

36. Fong H, Chun I, Reneker DH (1999) Beaded nanofibers formed during electrospinning. Polymer 40: 4585-4592.

37. Hohman MM, Shin YM, Rutledge G, Brenner MP (2001) Electrospinning and electrically forced jets. II. Applications Phys Fluids 13: 2221-2236.

38. Deitzel JM, Kleinmeyer J, Harris D, Beck NC (2001) The effect of processing variables on the morphology of elecrospun nanofibers and textiles. Polymer. 42: $261-272$.

39. Sun B, Duan B, Yuan X (2006) Preparation of core/shell PVP/PLA ultrafine fibers by coaxial electrospinning. J Appl Polym Sci 102: 39-45

40. Loscertales IG, Barrero A, Márquez M, Spretz R, Velarde-Ortiz R, et al. (2004) Electrically forced coaxial nanojets for one-step hollow nanofiber design. J Am Chem Soc 126: 5376-5377.

41. Jiang H, Hu Y, Li Y, Zhao P, Zhu K, et al. (2005) A facile technique to prepare biodegradable coaxial electrospun nanofibers for controlled release of bioactive agents. J Control Release 108: 237-243.

42. Jiang H, Hu Y, Zhao P, Li Y, Zhu K (2006) Modulation of protein release from biodegradable core-shell structured fibers prepared by coaxial electrospinning. J Biomed Mater Res B Appl Biomater 79: 50-57.

43. Zhang YZ, Wang X, Feng Y, Lim CT, Ramakrishna S (2006) Coaxia electrospinning of (fluorescein isothiocyanate-conjugated bovin derum albumine) -encapsulated poly (-caprolactone) nanofibers for sustained release. Biomacromol. 7: 1049-1057.

44. Song T, Zhang YZ, Zhou TJ (2006) Fabrication of magnetic composite nanofibers of poly (-caprolactone) with FePt nanoparticles by coaxial electrospinning. J Magn Magn Mater. 303: e286-e289.
45. Xu X, Yang L, Xu X, Wang X, Chen X, et al. (2005) Ultrafine medicated fibers electrospun from W/O emulsions. J Control Release 108: 33-42.

46. Xu XL, Zhuang XL, Chen XS, Wang XR, Yang LX, et al. (2006) Preparation of core-sheath composite nanofibers by emulsion electrospinning. Macromo Rapid Comm. 27: 1637-1642.

47. Xu X, Chen X, Ma P, Wang X, Jing X (2008) The release behavior of doxorubicin hydrochloride from medicated fibers prepared by emulsion-electrospinning. Eur J Pharm Biopharm 70: 165-170.

48. Xu X, Chen X, Wang Z, Jing X (2009) Ultrafine PEG-PLA fibers loaded with both paclitaxel and doxorubicin hydrochloride and their in vitro cytotoxicity. Eur J Pharm Biopharm 72: 18-25.

49. Yan S, Xiaoqiang L, Shuiping L, Xiumei M, Ramakrishna S (2009) Controlled release of dual drugs from emulsion electrospun nanofibrous mats. Colloids Surf B Biointerfaces 73: 376-381.

50. Yang Y, Li X, Cui W, Zhou S, Tan R, et al. (2008) Structural stability and release profiles of proteins from core-shell poly (DL-lactide) ultrafine fibers prepared by emulsion electrospinning. J Biomed Mater Res A 86: 374-385.

51. Yang Y, Li X, Qi M, Zhou S, Weng J (2008) Release pattern and structura integrity of lysozyme encapsulated in core-sheath structured poly(DL-lactide) ultrafine fibers prepared by emulsion electrospinning. Eur $\mathrm{J}$ Pharm Biopharm 69: $106-116$.

52. Chew SY, Wen J, Yim EK, Leong KW (2005) Sustained release of proteins from electrospun biodegradable fibers. Biomacromolecules 6: 2017-2024.

53. Li X, Su Y, Zhou X, Mo X (2009) Distribution of Sorbitan Monooleate in poly(Llactide-co-epsilon-caprolactone) nanofibers from emulsion electrospinning Colloids Surf B Biointerfaces 69: 221-224.

54. Liao Y, Zhang L, Gao Y, Zhu ZT, Fong H (2008) Preparation, characterization, and encapsulation/release studies of a composite nanofiber mat electrospun from an emulsion containing poly (lactic-co-glycolic acid). Polymer (Guildf) 49: 5294-5299.

55. Li XR, Zhang H, Li H, Tang GW, Zhao YH, Yuan XY (2008) Self-accelerated biodegradation of electrospun poly(ethylene glycol)-poly(L-lactide) membranes by loading proteinase K. Polym Degrad Stab 93: 618-626.

56. Angeles M, Cheng HL, Velankar SS (2008) Emulsion electrospinning: composite fibers from drop breakup during electrospinning. Polym Adv Techno 19: $728-733$.

57. Huang ZM, He CL, Yang A, Zhang Y, Han XJ, et al. (2006) Encapsulating drugs in biodegradable ultrafine fibers through co-axial electrospinning. $\mathrm{J}$ Biomed Mater Res A 77: 169-179.

58. Jiang H, Hu Y, Li Y, Zhao P, Zhu K, et al. (2005) A facile technique to prepare biodegradable coaxial electrospun nanofibers for controlled release of bioactive agents. J Control Release 108: 237-243.

59. Lu Y, Jiang H, Tu K, Wang L (2009) Mild immobilization of diverse macromolecular bioactive agents onto multifunctional fibrous membranes prepared by coaxial electrospinning. Acta Biomater 5: 1562-1574.

60. Zhang YZ, Venugopal J, Huang ZM, Lim CT, Ramakrishna S (2005) Characterization of the surface biocompatibility of the electrospun PCLcollagen nanofibers using fibroblasts. Biomacromolecules 6: 2583-2589.

61. Zhao P, Jiang H, Pan H, Zhu K, Chen W (2007) Biodegradable fibrous scaffolds composed of gelatin coated poly(epsilon-caprolactone) prepared by coaxial electrospinning. J Biomed Mater Res A 83: 372-382.

62. Zhang YZ, Huang ZM, Xu XJ, Lim CT, Ramakrishna S (2004) Preparation of core-shell structured PCL-r-gelatin bi-component nanofibers by coaxial electrospinning. Chem Mater 16: 3406-3409.

63. He CL, Huang ZM, Han XJ (2009) Fabrication of drug-loaded electrospun aligned fibrous threads for suture applications. J Biomed Mater Res A 89: 8095.

64. Díaz JE, Barrero A, Márquez M, Loscertales IG (2006) Controlled encapsulation of hydrophobic liquids in hydrophilic polymer nanofibers by co-electrospinning Adv Funct Mater 16: 2110-2116.

65. Larsen G, Spretz R, Velarde-Ortiz R (2004) Use of coaxial gas jackets to stablilize Taylor cones of volatile solutions and to induce particle- to-fiber transitions. Adv Mater 16: 166-169. 
Citation: Elahi MF, Lu W, Guoping G, Khan F (2013) Core-shell Fibers for Biomedical Applications-A Review. J Bioengineer \& Biomedical Sci 3: 121. doi:10.4172/2155-9538.1000121

Page 14 of 14

66. Chen SL, Hou HQ, Hu P, Wendorff JH, Greiner A, et al. (2009) Polymeric nanosprings by bicomponent electrospinning. Macromol Mater Eng 294: 265271

67. He CL, Huang ZM, Han XJ, Liu L, Zhang HS, et al. (2006) Coaxial electrospun poly(L-lactic acid) ultrafine fibers for sustained drug delivery. Journal of Macromolecular Science: 515-524.

68. Jiang H, Hu Y, Zhao P, Li Y, Zhu K (2006) Modulation of protein release from biodegradable core-shell structured fibers prepared by coaxial electrospinning. J Biomed Mater Res B Appl Biomater 79: 50-57.

69. Jo E, Lee S, Kim KT, Won YS, Kim HS, et al. (2009) Core-sheath nanofibers containing colloidal arrays in the core for programmable multi-agent delivery. Adv Mater 21: 968-972.

70. Qi H, Hu P, Xu J, Wang A (2006) Encapsulation of drug reservoirs in fibers by emulsion electrospinning: morphology characterization and preliminary release assessment. Biomacromolecules 7: 2327-2330.

71. Nie H, Soh BW, Fu YC, Wang CH (2008) Three-dimensional fibrous PLGA/HAp composite scaffold for BMP-2 delivery. Biotechnol Bioeng 99: 223-234.

72. Arumuganathar S, Irvine S, McEwan JR, Jayasinghe SN (2008) A novel direct aerodynamically assisted threading methodology for generating biologically viable microthreads encapsulating living primary cells. J Appl Polym Sci 107: 1215-1225.

73. Yi F, LaVan DA (2008) Poly(glycerol sebacate) nanofiber scaffolds by core/shell electrospinning. Macromol Biosci 8: 803-806.

74. Li S, Sun B, Li X, Yuan X (2008) Characterization of electrospun core/ shell poly(vinyl pyrrolidone)/poly(L-lactide-co-epsilon-caprolactone) fibrous membranes and their cytocompatibility in vitro. J Biomater Sci Polym Ed 19: 245-258.

75. Li H, Zhao C, Wang Z, Zhang H, Yuan X, et al. (2010) Controlled release of PDGF-bb by coaxial electrospun dextran/poly(L-lactide-co-epsiloncaprolactone) fibers with an ultrafine core/shell structure. J Biomater Sci Polym Ed 21: 803-819.

76. Liao IC, Chew SY, Leong KW (2006) Aligned core-shell nanofibers delivering bioactive proteins. Nanomedicine (Lond) 1: 465-471.

77. Fu YC, Nie H, Ho ML, Wang CK, Wang CH (2008) Optimized bone regeneration based on sustained release from three-dimensional fibrous PLGA/HAp composite scaffolds loaded with BMP-2. Biotechnol Bioeng 99: 996-1006.

78. Luu YK, Kim K, Hsiao BS, Chu B, Hadjiargyrou M (2003) Development of a nanostructured DNA delivery scaffold via electrospinning of PLGA and PLAPEG block copolymers. J Control Release 89: 341-353.

79. Liang D, Luu YK, Kim K, Hsiao BS, Hadjiargyrou M, et al. (2005) In vitro nonviral gene delivery with nanofibrous scaffolds. Nucleic Acids Res 33: e170.

80. Jiang H, Zhao P, Zhu K (2007) Fabrication and characterization of zein-based nanofibrous scaffolds by an electrospinning method. Macromol Biosci 7: 517525.

81. Wang M, Yu JH, Kaplan DL, Rutledge GC (2006) Production of submicron diameter silk fibers under benign processing conditions by two-fluid electrospinning. Macromolecules 39: 1102-1107. 